\title{
The pyrolytic decomposition of metal alkoxides (di-acetoxy-di-t-butoxy-silane, DADBS) during chemical vapour deposition of thin oxide films
}

\author{
R. Hofman, J.G.F. Westheim, V.A.C. Haanappel, T. Fransen and \\ P.J. Gellings \\ University of Twente, Department of Chemical Technology, Division of Currosion Science \\ and Inorganic Chemistry, P.O. Box 217, 7500 AE Enschede (The Netherlands)
}

(Received 10 June 1992)

\begin{abstract}
In this study the effects of the nature of metal alkoxides on their vapour pressures and thermal decomposition chemistry are reported. The vapour pressure and the volatility of a metal alkoxide strongly depends on the steric effect of its alkoxy group.

The thermal decomposition chemistry of one metal alkoxide (di-acetoxy-di-t-butoxysilane, DADBS) has been studied by mass spectrometry at temperatures between 423 and $923 \mathrm{~K}$. The pyrolytic products were acetic acid anhydride and 2 -methyl propene. The acetic acid anhydride is formed at temperatures above $473 \mathrm{~K}$ and 2-methyl propene is formed above $673 \mathrm{~K}$ by a $\beta$-hydride elimination mechanism. In these steps, a 6-ring intermediate is supposed to be formed. The silicon acid finally remaining is proposed to react by poly-condensation to $\mathrm{SiO}_{2}$ coatings or powder.
\end{abstract}

\section{INTRODUCTION}

Increasing interest in coating techniques such as metal-organic chemical vapour deposition (MOCVD) [1] has been observed recently. This technique involves deposition of a great variety of ceramic and metallic layers on various substrates to improve erosion, wear and corrosion resistance of the base materials. Even more important are the applications in the fabrication of electronic and optical devices, for which ultra-thin highly pure films are needed. In these fields low temperature techniques like MOCVD are essential to avoid unwanted high temperature reactions with the base materials.

An enormous amount of metal-organic compounds have been evaluated as possible precursors for coating formation $[2,3]$. The most ideal precursor should evaporate easily at a reasonable temperature and decompose to a

Correspondence to: T. Fransen, University of Twente, Department of Chemical Technology, Division of Corrosion Science and Inorganic Chemistry, P.O. Box 217, 7500 AE Enschede, Netherlands. 
solid coating at a sufficiently low temperature. Bradley et al. [2,3] discussed the volatility of the metal organic compounds regarding (1) the nature of the alkoxy group; (2) the nature of the metal atom; and (3) the nature of the oxygen-metal bond.

Much effort has been spent on the decomposition routes and mechanisms of the most common precursors, like aluminium tri-iso-propoxide (ATI) $[4,5]$ and tetraethyl orthosilicate (TEOS) $[6,7]$. For example, Nandi et al. [8] compared the decomposition chemistry of various titanium alkoxides, and Brieger et al. [9] did the same for aluminium alkoxides. It was reported that alcohols and ethers are the pyrolytic products. The formation of these products was explained by three different mechanisms: (1) $\alpha$-hydride elimination; (2) $\beta$-hydride elimination; and (3) a free radical mechanism.

Nandi et al. [8] reported that the alcohol/ether ratio increases significantly from primary to tertiary alkoxide groups. This is explained by the steric crowding of the $\alpha$-carbon atom favouring the $\beta$-hydride elimination mechanism.

$\mathrm{SiO}_{2}$ coatings are often prepared by MOCVD with TEOS as the precursor $[6,7]$. This compound requires, however, rather high deposition temperatures (about $1073 \mathrm{~K}$ ). This temperature can be reduced by using other CVD techniques, like laser CVD or plasma enhanced CVD, or by using another precursor such as DADBS, as suggested by Smolensky and Dean [10]. DADBS decomposes at a reasonably low temperature and the $\mathrm{SiO}_{2}$ deposition rate is acceptable at $650 \mathrm{~K}$. As far as is known, the decomposition mechanism of DADBS has not yet been reported.

In this paper the mechanism of the decomposition of the latter compound is discussed.

\section{THE VAPOUR PRESSURE OF METAL ALKOXIDES}

For the deposition of, for example, thin alumina and silica films by MOCVD, precursors with satisfactory stoichiometric requirements and favourable physical properties are needed. Metal alkoxides are the most promising precursors, but they have a strong affinity for water. Tri-alkyl metals are due to reactive and contain no oxygen for the deposition of thin oxide films by pyrolytic or thermolytic deposition. Because the precursor must be evaporated, the vapour pressure is an important property.

The vapour pressures of the aluminium alkoxides of interest are shown in Fig. 1 [1]. The results include the values of $a$ and $b$ in the equation $\log \left(p_{\mathrm{mm}}\right)=a-b / T$. Vapour pressures of other metal alkoxides based on $\mathrm{Zr}, \mathrm{Nb}, \mathrm{Ti}, \mathrm{Si}, \mathrm{B}$ and $\mathrm{Sb}$ are given by Sladek and Gibert [12].

Bradley $[2,3]$ reported that the volatility of metal alkoxides depends on (1) the nature of the alkoxy group, (2) the nature of the metal atom, and (3) the nature of the metal-oxygen-carbon bond.

The nature of the alkoxy group (implying its molecular size) influences the association between the molecules. In general, the steric effect of the 


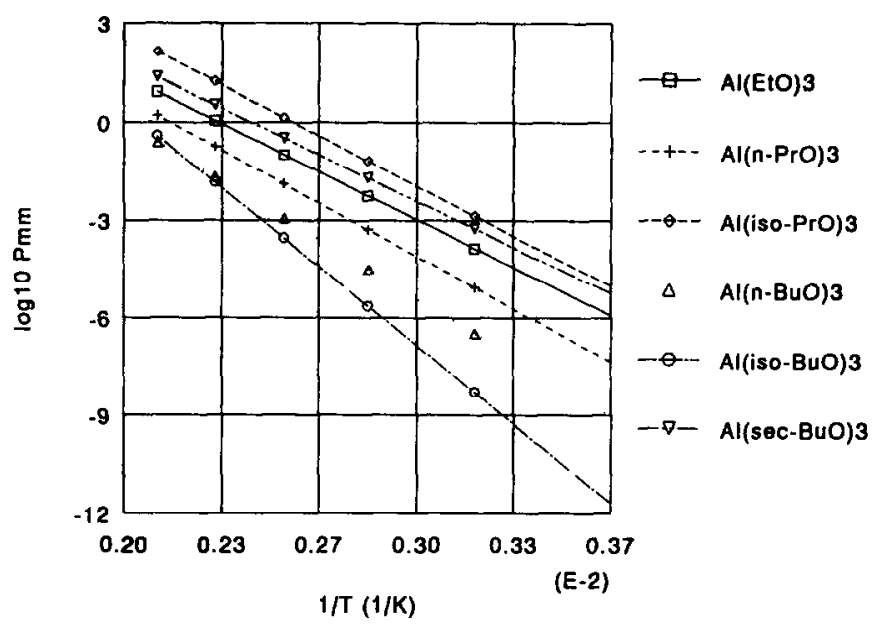

Fig. 1. Vapour pressures of aluminium alkoxides as functions of temperature [11].

alkyl groups is much more pronounced if the alkyl group is more bulky. If the metal alkoxides contain less bulky alkyl groups, their susceptibility to forming a certain degree of association increases.

The nature of the metal atom can also influence the volatility. For example, if the metal alkoxides contain monovalent or divalent metals, or the metal atomic radius is larger enough (the larger the metal, the bulkier will be the alkoxide group needed to prevent alkoxide bridging), the more the metal alkoxides are susceptible to forming oligomers (dimers, trimers and tetramers) by bridging oxygen and metal atoms. This implies that more energy and thus a higher evaporation temperature will be needed to make the metal alkoxide gaseous.

According to Bradley and co-workers [2,3] the electron releasing tendency also affects the degree of polymerization and thus the volatility of metal alkoxides. In this case, the bulkier the alkoxide group, the more polar the metal-oxygen-carbon bond is and thus the lower the volatility of the metal alkoxide.

On the basis of previous experience the precursor should easily evaporate (vapour pressure $=0.5-5 \mathrm{mmHg}$ ) at a reasonable temperature $(323-423 \mathrm{~K})$. If the higher temperatures are needed to bring the metal alkoxide into the gas phase, problems will occur related to the thermal stability of the metal alkoxide. Decomposition to a solid film should only take place on the surface of the substrate.

\section{EXPERIMENTAL}

The equipment used to study the decomposition mechanism has been described in a previous paper [3]. DADBS (Petrarch) is heated in a saturator at $353 \mathrm{~K}$. A nitrogen stream was used as the carrier gas bubbling 
TABLE 1

Values of $m / z$ for possible reaction products from the pyrolytic decomposition of DADBS

\begin{tabular}{llll}
\hline Compound & \multicolumn{2}{l}{ Peak } & \\
\cline { 2 - 4 } & 1st & 2nd & 3rd \\
\hline 2-Methylpropene & 41 & 56 & 55 \\
2-Methylpropanol & 59 & 41 & 31 \\
Acetic acid & 43 & 60 & 44 \\
Acetic acid anhydride & 43 & 42 & 44 \\
\hline
\end{tabular}

through the DADBS. The saturated gas stream was diluted by adding another nitrogen gas stream into the furnace. In this work the ratio of the gas stream through the DADBS to the diluting gas stream was maintained at 0.50 , and the total gas stream kept at $48 \mathrm{l} \mathrm{h}^{-1}$. A thermocouple was placed in the furnace to control the furnace temperature.

The composition of the outlet gas stream was recorded by a mass spectrometer (Masspec) as a function of the reactor temperature. Samples were taken every $15 \mathrm{~min}$ until the gas composition reached a steady-state value. At each temperature the intensity of several peaks was measured. A list of the scanned peaks (possible reaction products) is given in Table 1.

\section{RESULTS AND DISCUSSION}

Figure 2 shows the recorded peak intensities of acetic acid anhydride and 2-methylpropene as a function of temperature. The peak intensity of acetic acid $(m / z=60)$ and 2-methylpropanol never exceeded the detection limit. From these results it can be concluded that the thermolysis of DADBS takes place in three steps. In the first step $(T>473 \mathrm{~K})$ acetic acid anhydride
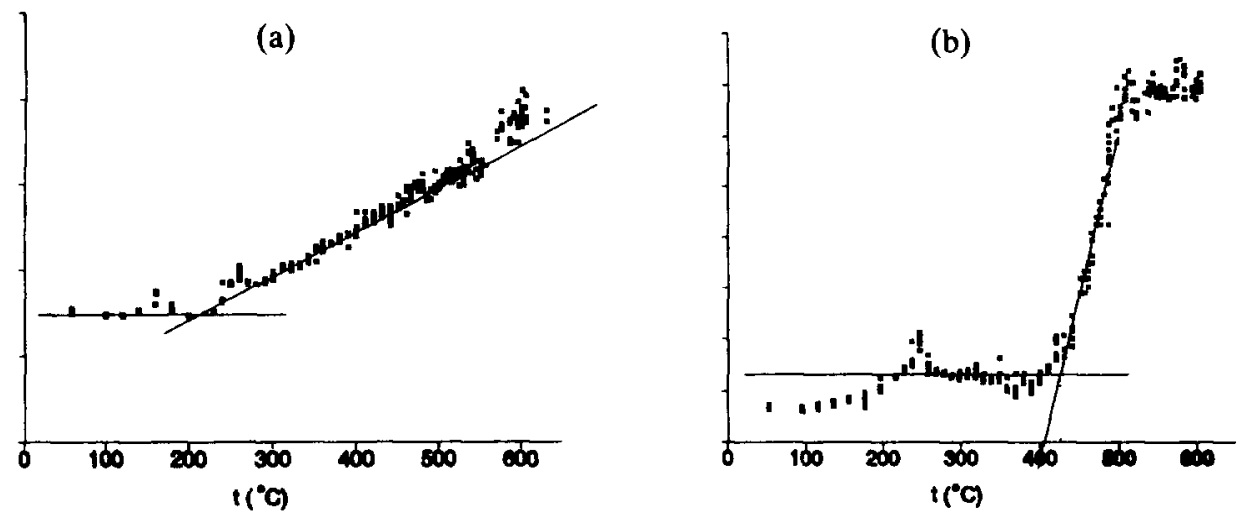

Fig. 2. Peak intensities (arbitrary units vs. temperature) of acetic acid anhydride (a) and 2-methyl propene (b). 


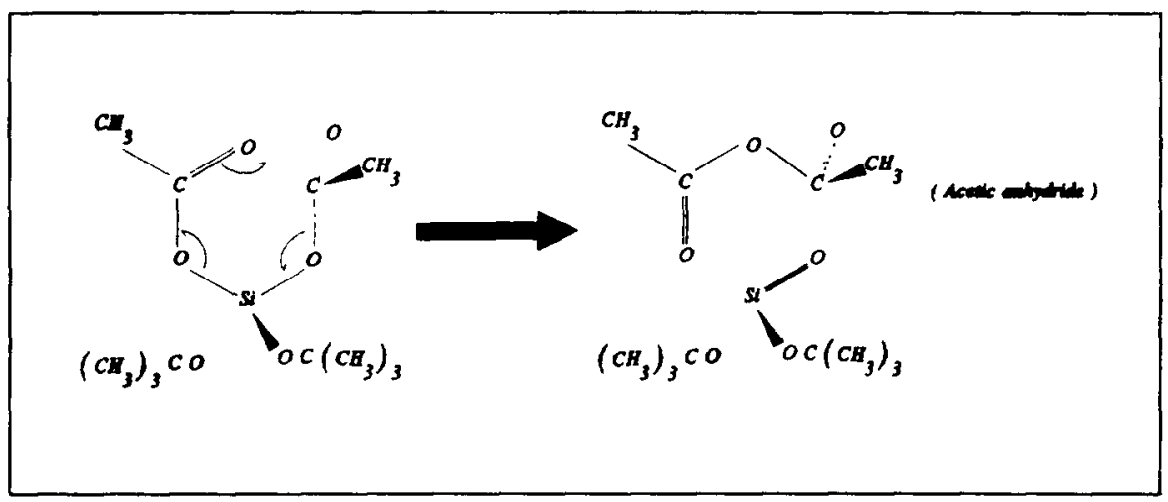

Step 1

$\left(\mathrm{CH}_{3}\right)_{3} \mathrm{CO}$
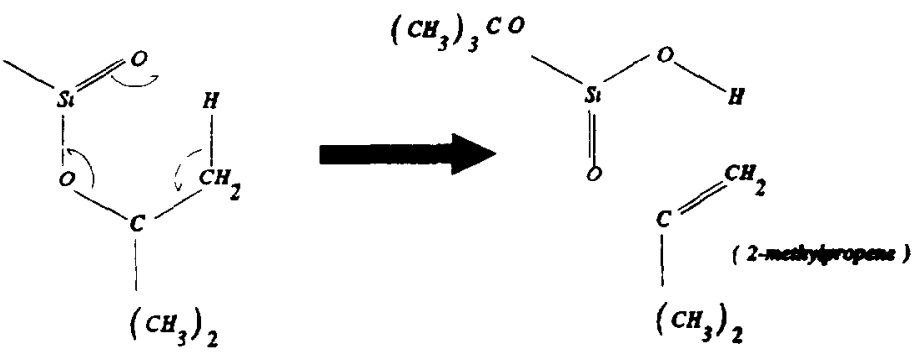

Step 2

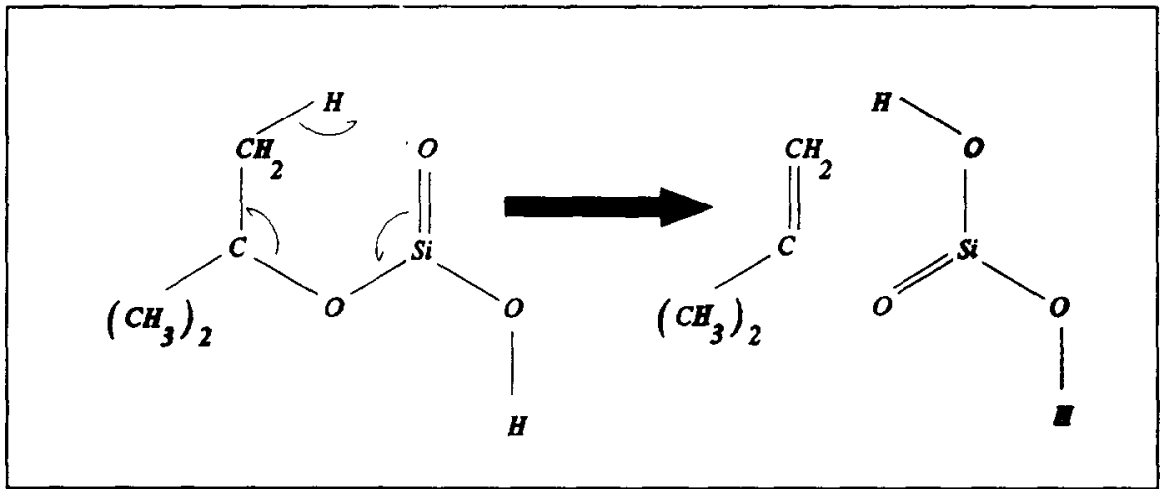

Step 3

Fig. 3. Proposed mechanism for the pyrolytic decomposition of DADBS. 
is formed; in the second step 2-methylpropene is formed $(T>673 \mathrm{~K})$; in the last step the remaining silicon acid is converted to silica by a polycondensation reaction.

The decomposition path can be explained by a mechanism proposed in Fig. 3. In the first step of this mechanism a rather stable 6-ring is formed by bridging the $\mathrm{C}=\mathrm{O}$ group from one acetic (IUPAC: ethanoic) group with the $\alpha$-carbon atom of the other acetic group. The second step, in which 2 -methylpropene is formed, can be described by a $\beta$-hydride elimination mechanism. When the $\alpha$-carbon atom becomes less accessible (steric crowding) $\beta$-hydride elimination becomes prevalent. Moreover, hydrogen atoms of large groups can easily attack the oxygen atoms of neighbouring groups. In the third step the remaining silicon acid will react either in the gas phase (homogeneous reaction) or on surfaces (heterogeneous reaction). This step involves a poly-condensation reaction to form a dense network of silica. In the case of a gas phase reaction, the product formed will be a powder, whereas surface reactions will lead to the formation of a thin coating. Indeed, in several MOCVD-reactors ceramic powders are formed as a by-product during layer growth on the substrate. Morssinkhof [4] reported powder formation at high deposition temperatures during MOCVD experiments to prepare $\mathrm{Al}_{2} \mathrm{O}_{3}$ coatings from ATI.

In both the first and the second step, an intramolecular reaction is supposed to take place. In these steps it is believed that a 6-ring is formed as an intermediate, in which the total charge can easily be redistributed, leading to cleavage at the weakest bonds in the ring. This model was also suggested by Ashby et al. [14] for the decomposition of metal alkoxides of magnesium, aluminium and zinc.

When the $\mathrm{C}_{\beta}-\mathrm{H}$ bond is weak compared to the $\mathrm{C}_{\alpha}-\mathrm{O}$ bond, the former bond is supposed to break; when the $\mathrm{C}_{\alpha}-\mathrm{O}$ bond is weak compared to the $\mathrm{C}_{\beta}-\mathrm{H}$ bond, the former bond should break. This model can also be used to explain the decomposition chemistry of other metal-organic compounds, such as aluminium tri-iso-propoxide, tetraethoxysilane and some titanium alkoxides.

\section{CONCLUSIONS}

It is the nature of the alkoxide group that mainly influences the vapour pressure and volatility of a metal alkoxide. To predict these physical properties the following factors must be taken into consideration: (1) the nature of the alkoxide groups; (2) the nature of the central metal atom; (3) the metal-oxygen-carbon bond.

Thermolysis of DADBS involves several steps in which acetic acid anhydride, 2-methylpropene, $\mathrm{SiO}_{2}$ and $\mathrm{H}_{2} \mathrm{O}$ are formed. In the first step acetic acid anhydride is formed above $453 \mathrm{~K}$. In the second step 2 -methylpropene is formed at temperatures above $673 \mathrm{~K}$ by a $\beta$-hydride 
elimination mechanism. In both steps a 6-ring is formed as an intermediate, allowing charges to flow freely. In the third step a poly-condensation reaction of silicon acid gives a dense amorphous silica layer or powder and water.

\section{ACKNOWLEDGEMENTS}

This research was supported by the Technology Foundation (STW) and the Dutch Innovative Research Programme on Technical Ceramics (IOP-TK). The authors thank Dr. V.T. Zaspalis for providing the mass spectrometer.

\section{REFERENCES}

1 H.E. Bryndza and W. Tam, Chem. Rev., 88 (1988) 1163.

2 D.C. Bradley, Chem. Rev., 89 (1989) 1317.

3 D.C. Bradley, R.C. Mehrotra and D.P. Gauer, Metal Alkoxides, Academic Press, London, 1978.

4 R. Morssinkhof, $\mathrm{PhD}$ Thesis, University of Twente, 1991.

5 M.K. Dongare and A.P.B. Sinha, Thermochim. Acta, 57 (1982) 37.

6 G.W. Heunisch, Anal. Chim. Acta, 48 (1969) 405.

7 S.B. Desu, J. Am. Ceram. Soc., 72 (1989) 1615.

8 M. Nandi, D. Rhubright and A. Sen, Inorg. Chem., 29 (1990) 3066.

9 G. Brieger, S.W. Watson, D.G. Barar and A.L. Shene, J. Org. Chem., 44 (1979) 1340.

10 G. Smolenksy and R.E. Dean, Mater. Lett., 4 (1986) 256.

11 R.C. Wilhoit, J. Phys. Chem., 61 (1957) 114.

12 K.J. Sladek and W.W. Gibert, Proc. Eur. Congr. on CVD (1972) 215.

13 R. Hofman, R.W.J. Morssinkhof, T. Fransen, J.G.F. Westheim and P.J. Gellings, Mater. Manuf. Processes, in press.

14 E.C. Ashby, G.F. Willard and A.B. Goel, J. Org. Chem., 44 (1979) 1221. 